\title{
ANÁLISE DOS BENEFÍCIOS E MODALIDADES DO SEGURO- DESEMPREGO NA REGIÃO METROPOLITANA DE MARINGÁ/PR
}

ANALYSIS OF BENEFITS AND INSURANCE MODALITIES UNEMPLOYMENT IN THE METROPOLITAN REGION OF MARINGÁ/PR

\author{
Danilo da Silva Fonseca \\ Centro Universitário Cidade Verde, PR, Brasil. \\ E-mail:daniloo_fonsecaa@hotmail.com \\ Marcela Bortotti Favero \\ Universidade Estadual de Maringá, PR, Brasil. \\ E-mail: favero.alipr@gmail.com \\ Camila Chirnev Caobianco \\ Centro Universitário Cidade Verde, PR, Brasil. \\ E-mail:prof_camila@fcv.edu.br \\ Eduardo Chierrito-Arruda \\ Centro Universitário Cidade Verde, PR, Brasil. \\ E-mail:prof_chierrito@fcv.edu.br
}

Recebido em: 06.03.2019 - Aceito em: 16.05.2019

DOI: http://dx.doi.org/10.5902/2526629237180

\section{RESUMO}

Este trabalho tem por objetivo fazer uma breve análise da quantidade de benefícios de Seguro-desemprego nas modalidades Formal e Empregado Doméstico concedidos na região metropolitana de Maringá/PR. Os dados são apresentados através de gráficos comparativos em forma de três grupos de cidades com o mesmo porte populacional, e, assim, faz-se uma breve análise das concessões desses benefícios e abordam-se também as leis que regulam o programa nas cinco modalidades existentes atualmente. São as modalidades: Seguro-Desemprego Trabalhador Formal, Seguro-Desemprego de Empregado Doméstico, Seguro-Desemprego de Trabalhador Resgatado, Seguro-Desemprego de Pescador Artesanal e Bolsa Qualificação. Também, esclarece-se sobre a instituição FAT (Fundo de Amparo ao Trabalhador), que é um fundo vinculado ao Ministério do Trabalho e Emprego que tem por objetivo principal custear o programa de seguro-desemprego e financiar programas de desenvolvimento socioeconômico, como cursos para capacitação profissional via Pronatec (Programa Nacional de Acesso ao Ensino Técnico e Emprego). Entre os resultados, destacou-se o impacto da seguridade para a categoria das domésticas, que conquistou direitos trabalhistas recentemente. Entre as análises, compreende-se que a modalidade Formal é a mais utilizada na região. Nas cidades de maior porte populacional (35 mil habitantes), foi 
perceptível um movimento em ascensão do uso de seguridade entre os anos de 2016 e 2017, período que reflete a crise política e econômica nacional. Este estudo revelou a urgência de garantir direitos trabalhistas, principalmente para grupos sociais que são excluídos da possibilidade de trabalhos formais, como era o caso das domésticas.

PALAVRAS-CHAVE: Seguro-Desemprego; Modalidade; Requisitos.

\section{ABSTRACT}

This study aims to make a brief analysis of the amount of Unemployment Insurance benefits in the Formal and Domestic Employee modalities granted in the metropolitan region of Maringá/PR, showing through comparative graphs in the form of three groups of cities with the same size population and thus making a brief analysis on the concessions of these benefits, and also to address the laws that regulate the program in the five modalities currently in existence, namely: Formal Unemployment Insurance, Domestic Employee Unemployment Insurance, Unemployment Insurance for Redeemed Workers, Unemployment Insurance Artisanal Fisherman and Scholarship, also explaining the institution of the FAT (Workers' Assistance Fund), which is a fund linked to the Ministry of Labor and Employment, whose main objective is to pay for the Unemployment Insurance program and the financing of socioeconomic development programs, as training courses for professional, fur PRONATEC. Among the results, the impact of security for the category of domestic workers, which recently gained labor rights, was highlighted. Among the analyzes, it is understood that the formal modality is the most used in the region. In cities with a larger population (35 thousand inhabitants), there was a growing movement in the use of security between the years 2016 and 2017, a period that reflects the national political and economic crisis. This study revealed the urgent need to ensure labor rights, especially for social groups that are excluded from the possibility of formal work, as was the case of domestic.

KEYWORDS: Unemployment Insurance; Modality. Requirements.

\section{INTRODUÇÃO}

Criado em 1986, pelo então presidente da República, José Sarney, o Programa de Seguro-Desemprego brasileiro tem por finalidade promover assistência financeira temporária ao trabalhador desempregado em virtude de dispensa sem justa causa, inclusive a indireta, e ao trabalhador comprovadamente resgatado de regime de trabalho forçado ou de condição análoga à escravidão. 
As políticas de emprego podem ser definidas como um conjunto de medidas que visam alterar, de forma mais ou menos direta, a oferta ou demanda por trabalho. A criação de postos públicos de emprego é exemplo de políticas diretas, enquanto a formação profissional da população constitui uma política de emprego menos direta. Não fazem parte desse arcabouço políticas macroeconômicas ou mudanças na legislação do mercado de trabalho, bem como modificações do salário-mínimo (Ramos, 2003). Nesse contexto, o programa pode ser considerado uma política de emprego passiva, pois visa amenizar a situação de desempregado e aumentar o bem-estar dos trabalhadores.

O seguro-desemprego em questão tem por principal objetivo auxiliar os trabalhadores na busca e preservação do emprego, promovendo, para tanto, ações integradas de orientação, recolocação e qualificação profissional. Apesar de se tratar de um benefício previdenciário, o Programa do Seguro-Desemprego não é administrado pelo Instituto Nacional de Seguro Social (INSS), mas sim pelo Ministério do Trabalho e Emprego (MTE).

Atualmente, existem cinco modalidades de seguro-desemprego, que serão abordadas neste artigo, sendo elas: Seguro-Desemprego Formal, Seguro-Desemprego Pescador Artesanal, Bolsa Qualificação, Seguro-Desemprego Empregado Doméstico e Seguro-Desemprego de Trabalhador Resgatado. Além disso, foi feita uma análise quantitativa dos benefícios concedidos na modalidade Formal e de Empregado Doméstico na região metropolitana de Maringá. O objetivo principal deste artigo é elucidar dúvidas sobre o programa e apurar, de forma quantitativa, quais cidades dessa região utilizaram esse benefício de 2013 até 2017.

\section{REVISÃO DA LITERATURA}

Para se compreender o benefício do Programa de Seguro-Desemprego, é necessário exemplificar as cinco modalidades que existem atualmente. Também é esclarecido o contexto histórico no qual surgiu o benefício e quando ele foi efetivamente implantado.

\subsection{Seguro-desemprego}

O Seguro-Desemprego é um programa do Governo Federal subsidiado pelo Fundo de Amparo ao Trabalhador (FAT), que ocorre em virtude de desligamento do trabalhador da empresa sem justa causa (contra a vontade do funcionário) e de maneira indireta (quando o empregado solicita judicialmente a dispensa do trabalho, com a alegação de que seu empregador não está cumprindo com as dis- 
posições assinadas em contrato de trabalho, e em outras modalidades descritas juntamente ao artigo 483 da Consolidação das Leis do Trabalho - CLT, tratandose de um rol taxativo).

A política de Seguro-Desemprego foi criada em um contexto histórico de bem-estar social, no período posterior à Segunda Guerra Mundial em países desenvolvidos, no qual se buscava o pleno emprego. O desemprego era, portanto, uma condição resultante de problemas particulares ou circunstanciais. No caso brasileiro, o Seguro-Desemprego foi introduzido em 1986 (Ramos, 2003).

Esse benefício insere-se em um conjunto de políticas de trabalho, renda e emprego, tendo como objetivo o auxílio financeiro temporário às pessoas desempregadas involuntariamente, sem justa causa, bem como a orientação e qualificação profissional de tais indivíduos. Por um lado, o programa é um avanço em termos de benefícios sociais; por outro, ainda é restrito aos trabalhadores formais, o que constitui um desafio à proteção social (Neto \& Zybertajn, 1999).

Algumas condições para que a pessoa possa receber o Seguro-Desemprego são: ter recebido salário nos últimos seis meses, ter trabalhado com carteira assinada em pelo menos seis meses dos últimos 36 meses, não ter recebido nenhum benefício da Previdência Social e não ter renda própria (Amorim \& Gonzalez, 2009).

Atualmente, existem cinco modalidades de Seguro-Desemprego, que serão apresentadas e exemplificadas a seguir.

\subsection{Formal}

O Seguro-Desemprego Formal foi instituído pela Lei $n^{\circ} 7.998$, de 11 de janeiro de 1990, pelo presidente José Sarney; alterado pela Lei $n^{\circ} 8.900$, de 30 de junho de 1994, pelo presidente Itamar Franco; e posteriormente pela Lei $n^{\circ}$ 13.134, de 16 de junho de 2015, pela presidente Dilma Rousseff. Essa norma tem como objetivo prover assistência financeira temporária a trabalhadores desempregados sem justa causa e auxiliá-los na manutenção e na busca de emprego, providenciando, para tanto, ações integradas de orientação, recolocação e qualificação profissional (Santos, 2018).

O programa é gerido em parceria com o MTE e o Sistema Nacional de Emprego (Sine), onde se dá entrada às solicitações de benefício e também se encaminha para vagas de trabalho com o mesmo Cadastro Brasileiro de Ocupações $(\mathrm{CBO})$ e, até mesmo, para cursos profissionalizantes através do programa Progra- 
ma Nacional de Acesso ao Ensino Técnico e Emprego (Pronatec). Assim, profissionalizam-se novos trabalhadores para seus empregos futuros.

A quantidade de parcelas a que o trabalhador tem direito depende de dois aspectos: a quantidade de meses trabalhados e a quantidade de vezes que o trabalhador já requereu o benefício, conforme exemplificado pelo Quadro 1, obtido no portal do MTE:

Quadro 1-Quantidade de parcelas segundo o MTE

\begin{tabular}{|c|c|c|}
\hline Solicitação & Exigências & $\mathrm{N}^{\circ}$ de parcelas \\
\hline Primeira & $\begin{array}{l}\text { O trabalhador deve comprovar vínculo empre- } \\
\text { gatício com pessoa jurídica ou física por no mi- } \\
\text { nimo } 18 \text { e no máximo } 23 \text { meses no período de } \\
\text { referência. } \\
\text { O trabalhador deve comprovar vínculo empre- } \\
\text { gatício com pessoa jurídica ou física de no mí- } \\
\text { nimo } 24 \text { meses no período de referência. }\end{array}$ & Quatro \\
\hline Segunda & $\begin{array}{l}\text { O trabalhador deve comprovar vínculo empre- } \\
\text { gatício com pessoa jurídica ou física de no mí- } \\
\text { nimo nove meses e no máximo } 11 \text { meses no } \\
\text { período de referência. } \\
\text { O trabalhador deve comprovar vínculo em- } \\
\text { pregatício com pessoa jurídica ou física de no } \\
\text { mínimo } 12 \text { meses e no máximo } 23 \text { meses no } \\
\text { período de referência. } \\
\text { O trabalhador deve comprovar vínculo empre- } \\
\text { gatício com pessoa jurídica ou física de no mí- } \\
\text { nimo } 24 \text { meses no período de referência. }\end{array}$ & Quatro \\
\hline Terceira ou mais & $\begin{array}{l}\text { O trabalhador deve comprovar vínculo empre- } \\
\text { gatício com pessoa jurídica ou física de no mí- } \\
\text { nimo seis e no máximo } 11 \text { meses no período } \\
\text { de referência. } \\
\text { O trabalhador deve comprovar vínculo empre- } \\
\text { gatício com pessoa jurídica ou física de no mí- } \\
\text { nimo } 12 \text { e no máximo } 23 \text { meses no período de } \\
\text { referência. } \\
\text { O trabalhador deve comprovar vínculo empre- } \\
\text { gatício com pessoa jurídica ou física de no mí- } \\
\text { nimo } 24 \text { no período de referência. }\end{array}$ & Quatro \\
\hline
\end{tabular}

Fonte: adaptado de Seguro-Desemprego Formal, do Portal do Ministério do Trabalho e Emprego, 2016.

Para receber o benefício do Seguro-Desemprego, o cálculo é feito com base na média dos três últimos salários do trabalhador. Para quem recebeu uma média salarial de até $R \$ 1.360,70$, multiplica-se o salário por 0,8 ou $80 \%$ para se saber o valor. Na segunda faixa, o que exceder $\mathrm{R} \$ 1.360,70$, multiplica-se por 0,5 ou $50 \%$ 
e somam-se $R \$ 1.088,56$. E na terceira faixa, para quem obteve média salarial acima de $R \$ 2.268,05$, o valor será de $R \$ 1.542,24$ invariavelmente (Santos, 2018).

Quadro 2 - Faixas de salário exemplificando o valor de cada parcela

\begin{tabular}{|c|c|}
\hline Faixas de salário médio & Valor da parcela \\
\hline Até $\mathrm{R} \$ 1.360,70$ & Multiplica-se o salário médio por $0,8(80 \%)$. \\
\hline De $\mathrm{R} \$ 1.360,71$ até $\mathrm{R} \$ 2.268,05$ & $\begin{array}{c}\text { O que exceder } \mathrm{R} \$ 1.360,70, \text { multiplica-se por } \\
0,5(50 \%) \text { e somam-se } \mathrm{R} \$ 1.088,56 . \\
\text { O valor da parcela será de } \mathrm{R} \$ 1.542,24 \\
\text { invariavelmente. }\end{array}$ \\
\hline Acima de $\mathrm{R} \$ 2.268,05$ & \begin{tabular}{c} 
ingel \\
\hline
\end{tabular} \\
\hline
\end{tabular}

Fonte: adaptado de Seguro-Desemprego Formal, do Portal do Ministério do Trabalho e Emprego, 2016.

\subsection{Empregado Doméstico}

O Seguro-Desemprego Empregado Doméstico tem o mesmo objetivo do Seguro-Desemprego Formal, porém tem uma lei própria que regula o pagamento do benefício, e é instituído pela Lei $n^{\circ}$ 10.208, de 23 de março de 2001, e pela Lei Complementar $n^{\circ} 150$, de 02 de junho de 2014. Tem por finalidade prover assistência financeira temporária ao empregado doméstico dispensado sem justa causa. Por haver uma lei própria que regula o benefício na modalidade de requerente doméstico, o valor de cada parcela é de um salário-mínimo, independente de qual seria sua média dos três últimos salários de contribuição para a Previdência Social, e também se o segurado tem direito a no máximo três parcelas.

O empregado doméstico dispensado sem justa causa deve comprovar: (a) ter trabalhado como empregado doméstico por, pelo menos, 15 meses nos últimos 24 meses; (b) não estar recebendo nenhum benefício da Previdência Social, exceto auxílio-acidente e pensão por morte; e (c) não possuir renda própria para seu sustento e de sua família, como, por exemplo, empreendedor.

O valor do benefício para empregado doméstico se norteia pelo salário-mínimo vigente, e não pela média dos três últimos salários do Seguro-Desemprego Formal. A quantidade de parcelas também se diferencia, pois, para se adquirir direito ao Seguro-Desemprego para Empregado Doméstico, são necessários 15 meses de trabalho nos últimos 24 meses.

Já a respeito da quantidade de parcelas, independentemente do valor recebido pelo trabalhador e da quantidade de meses em que ele está registrado como empregado doméstico, ele terá direito a somente três parcelas. O prazo legal para se dar entrada no benefício de 7 a 90 dias a partir da data de dispensa. 


\subsection{Bolsa Qualificação Profissional}

A Bolsa de Qualificação Profissional é o benefício instituído pela Medida Provisória $\mathrm{n}^{\circ}$ 2.164-41, de 24 de agosto de 2001, pelo presidente Fernando Henrique Cardoso (vigente em consonância com o art. $2^{\circ}$ da emenda constitucional $n^{\circ}$ 32, de 11 de setembro de 2001). É uma política ativa que tem por objetivo principal subvencionar os trabalhadores, com contrato de trabalho suspenso, em conformidade com o disposto em convenção sindical ou acordo coletivo de trabalho, que estejam devidamente matriculados em curso ou programa de qualificação profissional oferecido pelo empregador.

A utilização desse benefício de seguro-desemprego visa dar apoio às empresas que estão com dificuldades orçamentárias, incentivando a redução de sua folha de pagamento, visto que o contrato de seu funcionário é suspenso, evitando, dessa forma, demissões em massa. Também, por outro lado, capacita-se o profissional que está recebendo o benefício, sendo, desse modo, vantajoso para ambas as partes. Evita-se, assim, uma retração ainda maior na capacidade produtiva da empresa, o que geraria grandes impactos no mercado de trabalho.

De acordo com Santos (2018), para o trabalhador ter direito a Bolsa Qualificação, ele terá que comprovar os requisitos previstos na Lei $n^{\circ} 7.998$, de 1990, e suas alterações, exceto a dispensa sem justa causa, quais sejam:

Art. 476-A. O contrato de trabalho poderá ser suspenso, por um período de dois a cinco meses, para participação do empregado em curso ou programa de Qualificação Profissional oferecido pelo empregador, com duração equivalente à suspensão contratual, mediante previsão em convenção ou acordo coletivo de trabalho e aquiescência formal do empregado, observado o disposto no art. 471 desta Consolidação.

$1^{\circ}$ Após a autorização concedida por intermédio de convenção ou acordo coletivo, o empregador deverá notificar o respectivo sindicato, com antecedência mínima de quinze dias da suspensão contratual.

$2^{\circ} \mathrm{O}$ contrato de trabalho não poderá ser suspenso em conformidade com o disposto no caput deste artigo mais de uma vez no período de dezesseis meses.

$3^{\circ} \mathrm{O}$ empregador poderá conceder ao empregado ajuda compensatória mensal, sem natureza salarial, durante período de suspensão contratual nos termos do caput deste artigo, com valor a ser definido em convenção ou acordo coletivo. 
$4^{\circ}$ Durante o período de suspensão contratual para participação em curso ou programa de Qualificação Profissional, o empregado fará jus aos benefícios voluntariamente concedidos pelo empregador.

$5^{\circ}$ Se ocorrer a dispensa do empregado no transcurso do período de suspensão contratual ou nos três meses subsequentes ao seu retorno ao trabalho, o empregador pagará ao empregado, além das parcelas indenizatórias previstas na legislação em vigor, multa a ser estabelecida em convenção ou acordo coletivo, sendo de, no mínimo, cem por cento sobre o valor da última remuneração mensal anterior à suspensão do contrato.

$6^{\circ}$ Se durante a suspensão do contrato não for ministrado o curso ou programa de Qualificação Profissional ou o empregado permanecer trabalhando para o empregador, ficará descaracterizada a suspensão, sujeitando o empregador ao pagamento imediato dos salários e dos encargos sociais referente ao período, às penalidades cabíveis previstas na legislação em vigor, bem como às sanções previstas em convenção ou acordo coletivo.

$7^{\circ} \mathrm{O}$ prazo limite fixado no caput poderá ser prorrogado mediante convenção ou acordo coletivo de trabalho e aquiescência formal do empregado, desde que o empregador arque com o ônus correspondente ao valor da Bolsa Qualificação Profissional no respectivo período.

Reitera-se que o contrato de trabalho só poderá ser suspenso caso a convenção coletiva na qual o trabalhador está amparado permitir tal ato, e com aviso prévio da suspensão contratual ao sindicato em até 15 dias antes de sua suspenção. A respeito da carga horária dos cursos, estes necessitam ter no mínimo $85 \%$ de ações formativas feitas em laboratórios, $15 \%$ de seminários e frequência mínima de $75 \%$ referente às atividades e presença.

Os requisitos para o seguro-desemprego na modalidade Bolsa Qualificação são: (a) deve existir dispositivo tratando do assunto em acordo ou convenção coletiva de trabalho, devidamente aceito pela entidade representativa da classe trabalhadora; (b) o acordo ou a convenção coletiva exige homologação nas unidades locais do Ministério do Trabalho e Emprego, ou seja, nas Superintendências Regionais do Trabalho e Emprego.

\subsection{Pescador Artesanal}

O Seguro-desemprego de Pescador Artesanal é destinado aos pescadores que atuem de maneira artesanal, individual ou em regime de 
economia familiar e que tenham que interromper a pesca devido ao período de proibição para preservação da espécie. Tem por objetivo principal promover assistência financeira ao pescador artesanal que teve suas atividades paralisadas no período defeso (piracema).

Para ser contemplado com essa modalidade de seguro, o pescador precisa cumprir os seguintes requisitos: (a) atuar sozinho ou em regime de economia familiar, exercendo a pesca de maneira ininterrupta; (b) estar impedido de pescar devido ao período de piracema; (c) ter cadastro ativo no Registro Geral de Pesca (RGP) há pelo menos um ano; (d) ser segurado especial da Previdência Social; (e) comercializar sua produção para pessoa física ou jurídica, comprovando a contribuição previdenciária nos últimos 12 meses imediatamente anteriores ao requerimento do benefício ou desde o último período de defeso até o início do período atual, o que for menor; (f) não estar em gozo de nenhum benefício de prestação continuada da Assistência Social ou da Previdência Social, exceto auxílio-acidente, auxílio-reclusão e pensão por morte; e (g) não ter vínculo empregatício.

\subsection{Trabalhador Resgatado}

O Seguro-Desemprego de Trabalhador Resgatado é um auxilio temporário concedido ao trabalhador que foi resgatado de regime de trabalho forçado ou de condição análoga ao trabalho escravo. O prazo legal para solicitação é de até 90 dias subsequentes à data do resgate, sendo que o valor a ser percebido pelo trabalhador resgatado é de um salário-mínimo.

As ocorrências de trabalho escravo no Brasil se aproximam do que a Organização Internacional do Trabalho (OIT) classifica como servidão por dívidas. Normalmente, o aliciamento dos trabalhadores, tarefa dos chamados "gatos", é feito distante da propriedade que utilizará a mão de obra para dificultar a fuga, consoante a Secretaria de Inspeção do Trabalho, do Ministério do Trabalho. Nessa hipótese, os trabalhadores não ganham praticamente nada de salário em espécie. Assim, sempre estão devendo para seus patrões. Além disso, os aliciados são obrigados a viver em situações degradantes, sem condições de higiene, sujeitos a intempéries e, em alguns casos, cercados por jagunços armados (Romero, 2003).

As denúncias dos trabalhadores que conseguem escapar são feitas normalmente à Comissão Pastoral da Terra (CPT) e às delegacias regionais do trabalho. 
Entretanto, a fuga não significa redenção, pois, em razão da falta de oportunidades e baixo nível de especialização, é comum que essas pessoas acabem sendo contratadas novamente, nas mesmas condições, em outras fazendas, formando um ciclo vicioso que precisa ser quebrado (Romero, 2003).

\section{METODOLOGIA}

No presente trabalho, foi realizada uma pesquisa, por meio quantitativo, de dados comparativos populacionais das cidades pertencentes à região metropolitana de Maringá/PR. Esses dados foram obtidos através do portal do Instituto Brasileiro de Geografia e Estatística (IBGE), de onde foi retirada a quantidade populacional das nove cidades tratadas neste trabalho, sendo divididas em três grupos populacionais, o primeiro grupo com o porte populacional de 5 mil habitantes, o segundo com 20 mil habitantes e, ao final, o terceiro com o porte populacional de 40 mil habitantes.

Feita a divisão dos grupos, foram realizadas análises na quantidade de benefícios concedidos para cada grupo de cidades entre os anos de 2013 e 2017, através da relação da quantidade de seguros-desemprego concedidos para essas populações, cujos dados retirados do site do MTE entre agosto e dezembro de 2018.

\section{ANÁLISE DOS BENEFÍCIOS FORMAIS CONCEDIDOS}

A análise apresenta um estudo comparativo das concessões de benefícios das cidades que compõem a região metropolitana de Maringá entre os anos de 2013 e 2017.

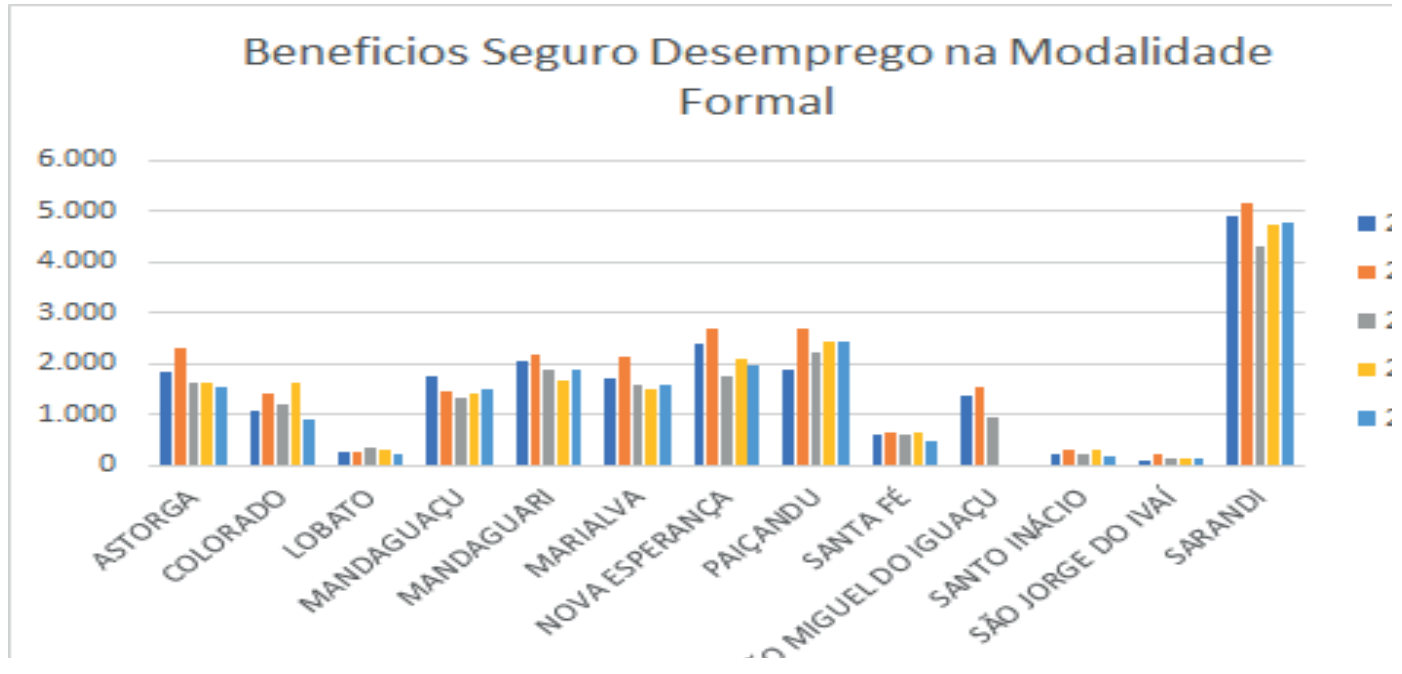

Figura 1 - Quantidade de benefícios do seguro-desemprego de 2013 a 2017 Fonte: dados retirados do Portal do MTE. 
A modalidade de Seguro-Desemprego Formal, entre as cinco modalidades vigentes atualmente, é a mais solicitada nos postos de atendimento do Sine e no MTE. Neste tópico, será realizada uma breve análise dessa modalidade na região selecionada para observação, comparando o número de beneficiários entre as cidades com a mesma faixa de habitantes, conforme a Tabela 1, e demonstrando a importância desse programa, tanto para quem recebe o benefício quanto para a cidade, pois o dinheiro que oriunda do requerente com benefício acaba girando no comércio local, movimentando, assim, a economia da cidade.

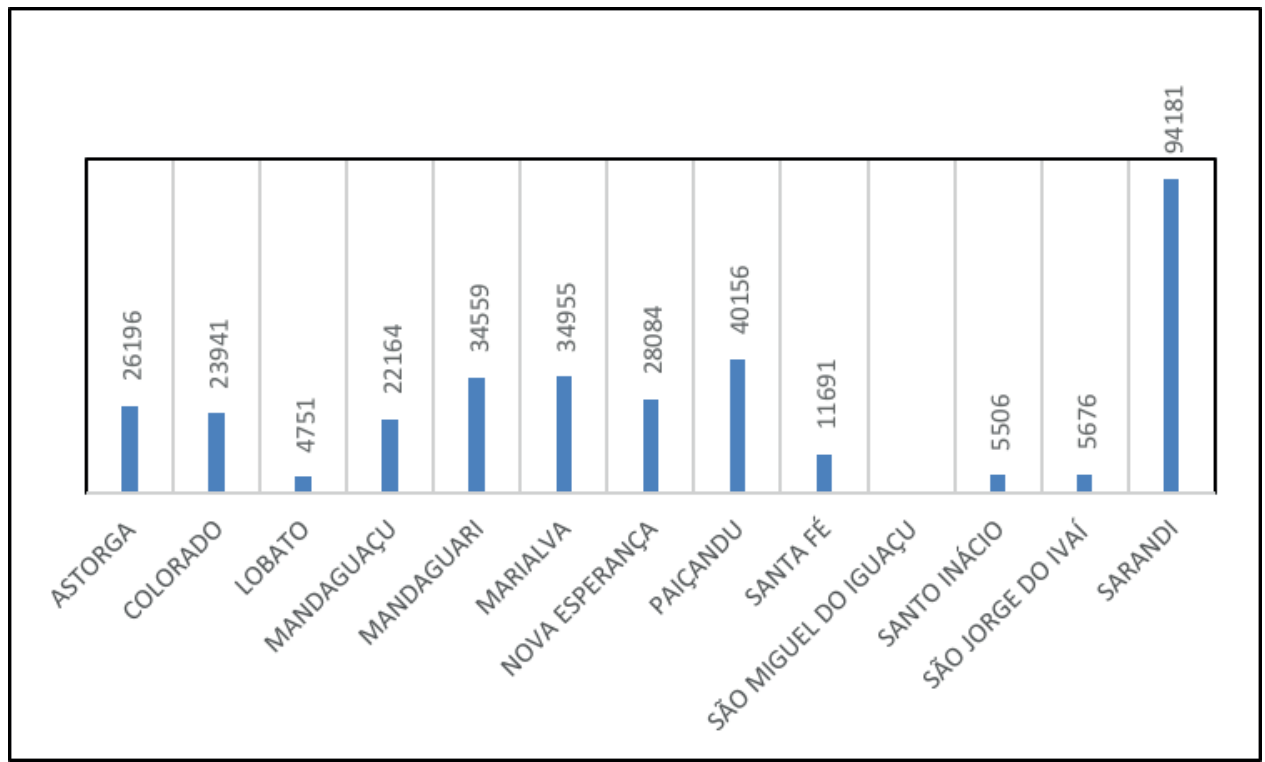

Figura 2 - Estimativa de população

Fonte: dados retirados do IBGE.

Com base na população de cada cidade da região, foi elaborada uma tabela com três grupos de cidades, com população equivalente, sendo, então, divididas em: Grupo 1, as cidades com porte de 5 mil habitantes, sendo elas Lobato, Santo Inácio e São Jorge do Ivaí; Grupo 2, as cidades com porte de 25 mil habitantes, sendo Astorga, Mandaguaçu e Nova Esperança; e, por fim, Grupo 3, as cidades na faixa de 35 mil habitantes, como é o caso de Mandaguari, Marialva e Paiçandu.

Tabela 1 - Distribuição das cidades em grupos

\begin{tabular}{|c|c|c|}
\hline Grupo 1 & Grupo 2 & Grupo 3 \\
\hline Lobato & Astorga & Mandaguari \\
\hline Santo Inácio & Mandaguaçu & Marialva \\
\hline São Jorge do Ivaí & Nova Esperança & Paiçandu \\
\hline
\end{tabular}

Fonte: dados retirados do IBGE. 


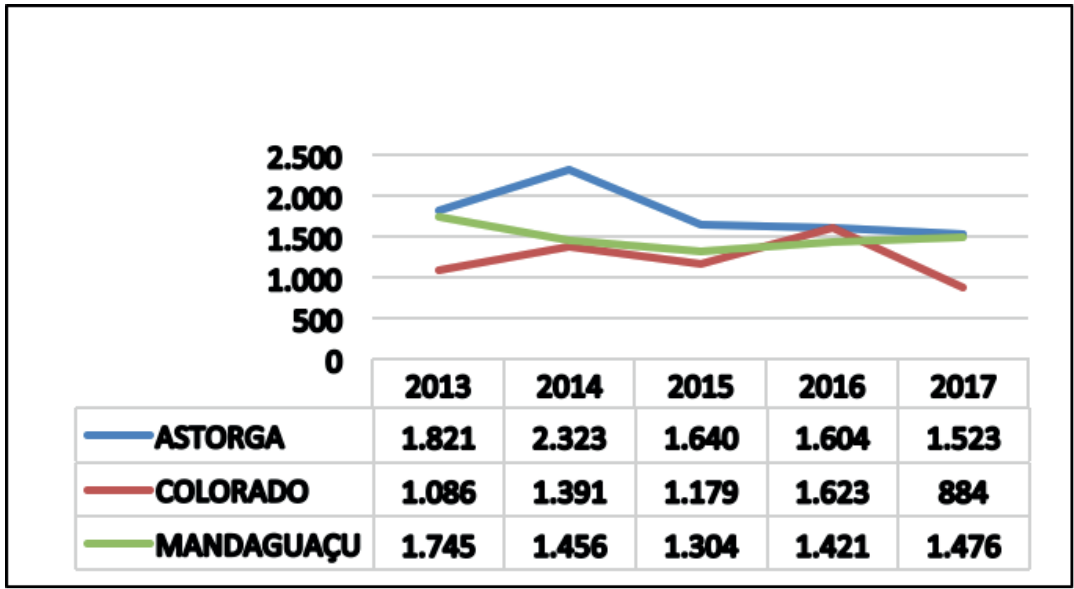

Figura 3 - Seguro-Desemprego Modalidade Formal Fonte: dados retirados do MTE.

Observa-se que houve um aumento no número de benefícios no ano de 2014 em comparação com o ano de 2013 nas três cidades com estimativa de população na faixa de 5 mil habitantes, sendo que a cidade de São Jorge do Ivaí registrou um aumento de $136 \%$ nesse mesmo período. Já no ano seguinte, de 2015 , registrou uma queda de $46 \%$ nos benefícios concedidos, seguida de um ligeiro aumento no ano de 2016 e uma nova queda no ano de 2017.

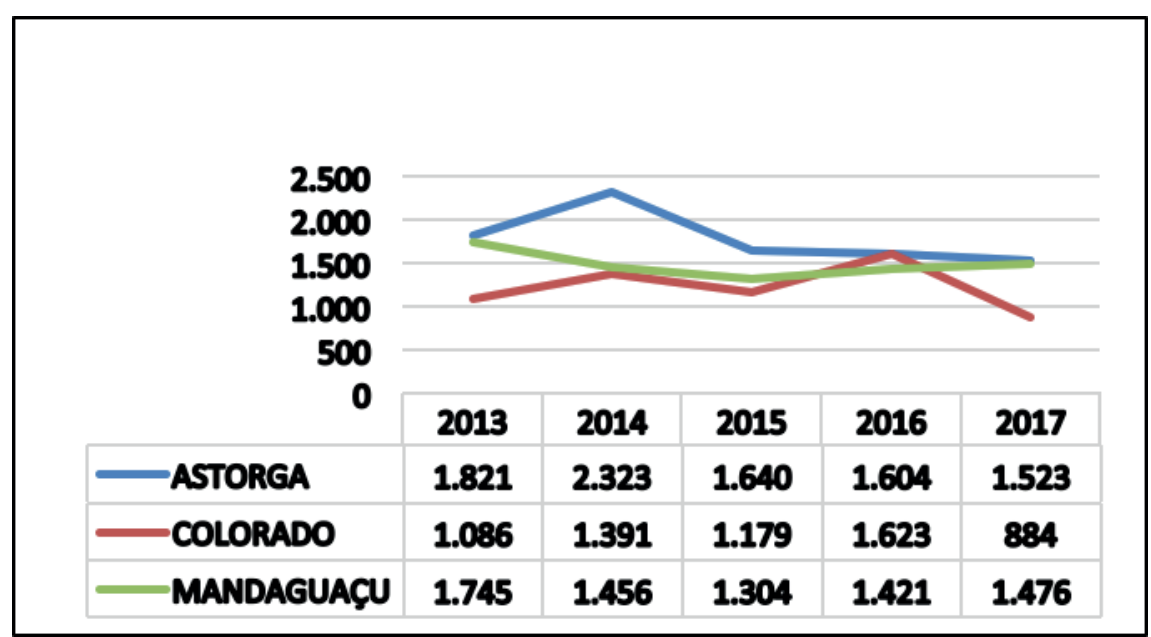

Figura 4 - Seguro-Desemprego Modalidade Formal Fonte: dados retirados do MTE. 
Quanto às três cidades com faixa de 25 mil habitantes, houve uma variação constante de um ano para o outro até o ano de 2015, verificando-se um aumento no número de benefícios concedidos na modalidade Formal no ano de $2014 \mathrm{em}$ comparação com o ano de 2013 e uma redução no ano de 2015, quando só a cidade de Astorga manteve a mesma quantidade de benefícios dos anos posteriores. Colorado e Mandaguaçu continuaram oscilando na quantidade de benefícios de um ano para o outro.

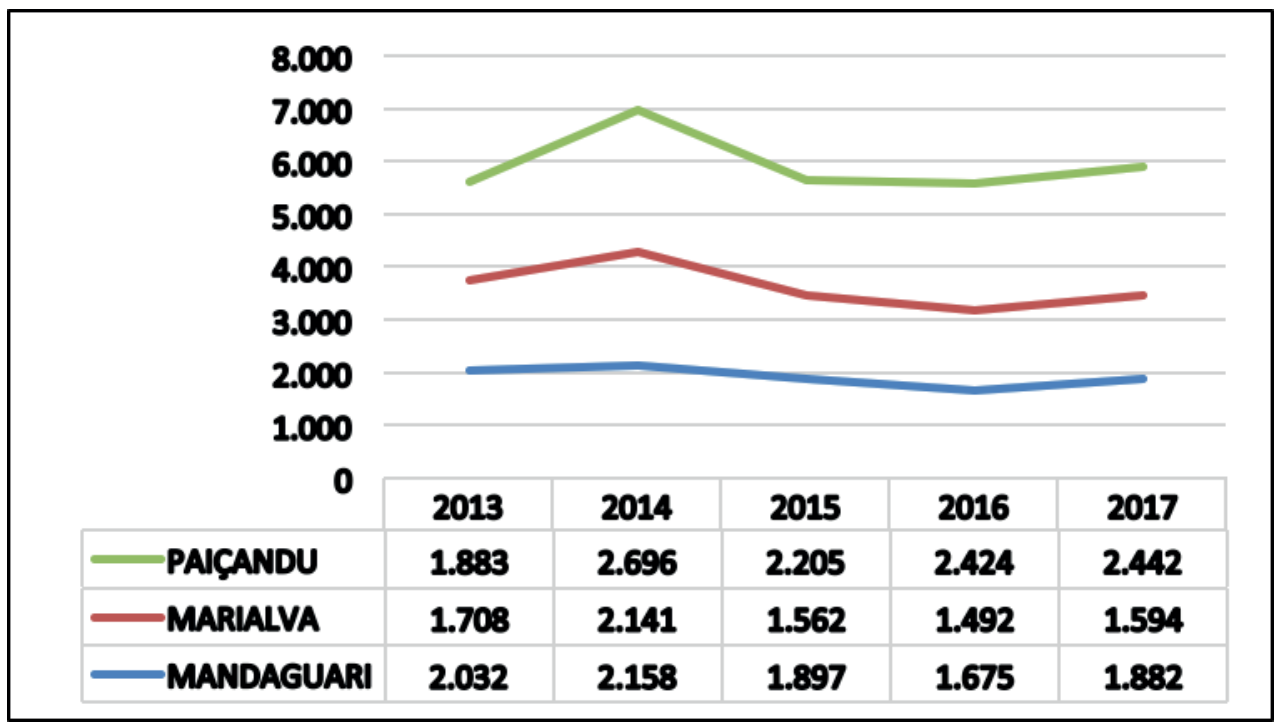

Figura 5 - Seguro-Desemprego Modalidade Formal Fonte: dados retirados do MTE.

Em relação às três cidades com o porte de 35 mil habitantes ou mais, elas estão ou coladas geograficamente ou bem próximas de Maringá. A isso se deve a quantidade de empregos que a metrópole gera para as cidades vizinhas e, devido a isso, mais emprego se gera nessa região e maior é a população que a cidade ostenta, consequentemente o número de benefícios do Seguro-Desemprego irá ser maior do que o das regiões com populações menores. Além disso, nas pequenas cidades, existem muitos empregos sem carteira assinada, não gerando, assim, benefício ao requerente. 


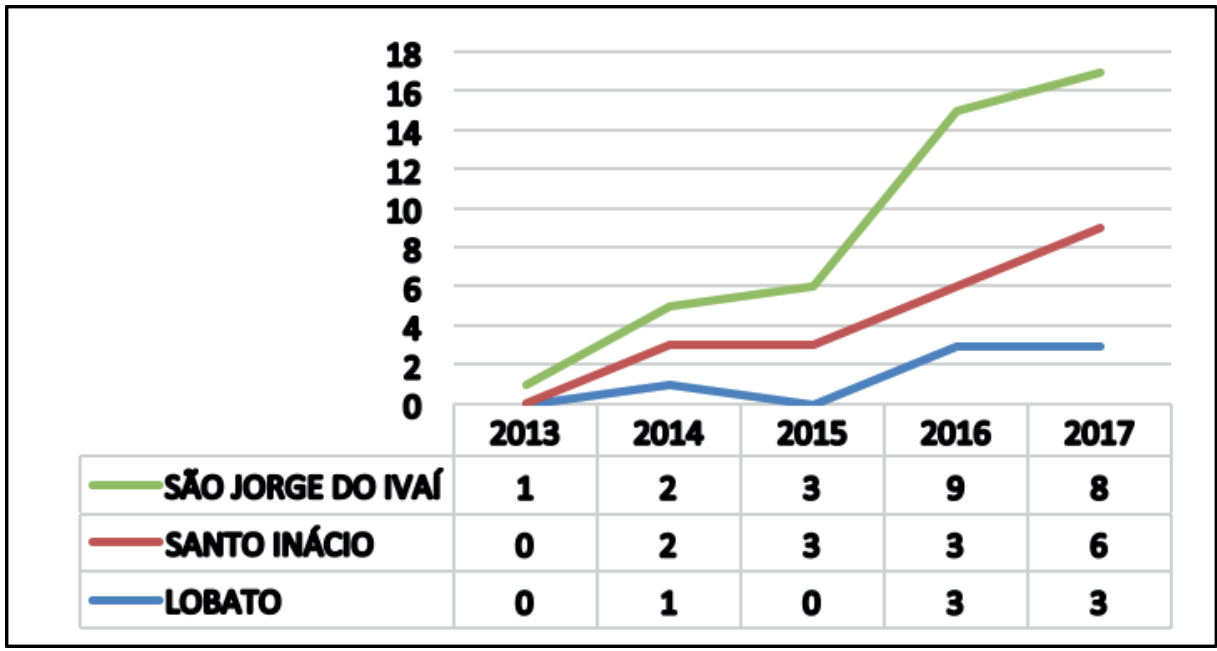

Figura 6 - Seguro-Desemprego Modalidade Doméstica Fonte: dados retirados do MTE.

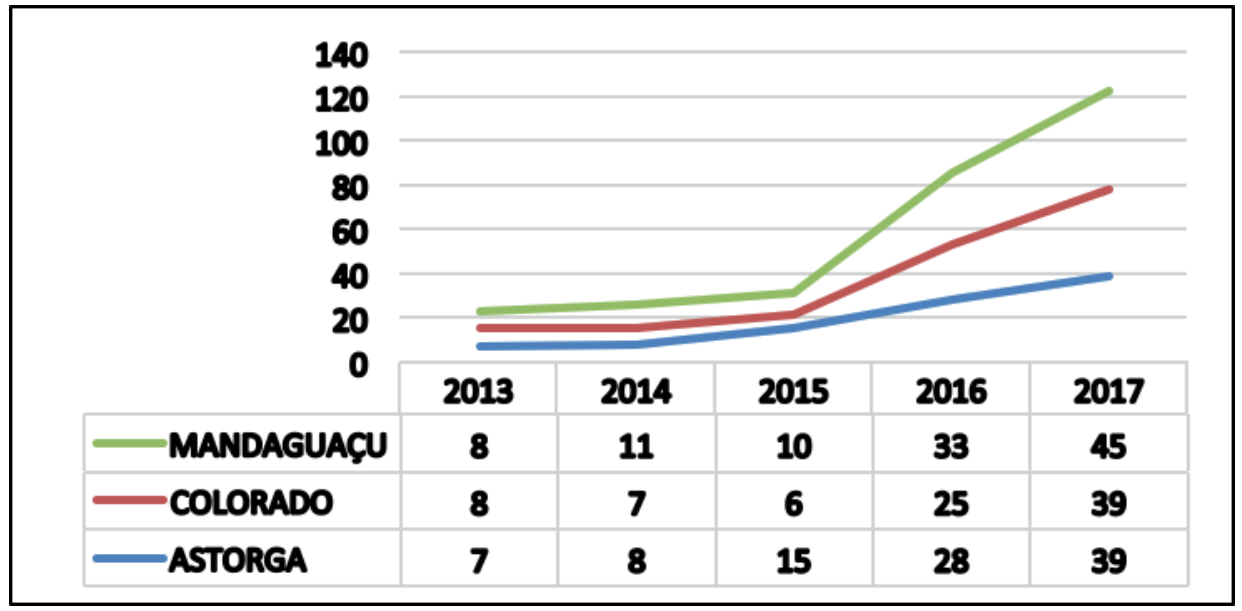

Figura 7 - Seguro-Desemprego Modalidade Doméstica Fonte: dados retirados do MTE. 


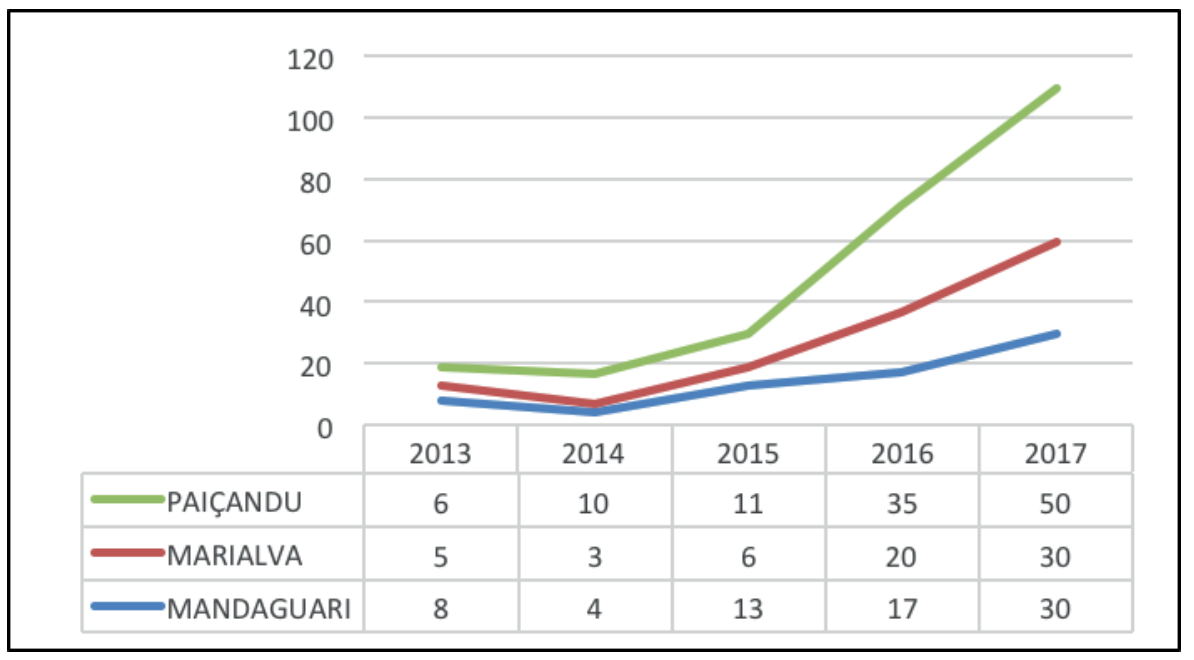

Figura 8 - Seguro-Desemprego Modalidade Doméstica Fonte: dados retirados do MTE.

As empregadas domésticas, até 1988, tinham poucos direitos trabalhistas, ou seja, a lei que as regia era a Lei $n^{\circ} 5.859 / 72$. Somente com a Constituição de 1988, o trabalho doméstico assalariado foi reconhecido, tornando-se um ponto de partida para a valorização da atividade doméstica como profissão. Mas foi apenas no ano de 2015, com a nova Lei da Empregada Doméstica, que tal setor profissional viu expandir os seus direitos trabalhistas, buscando-se uma sociedade mais justa e igualitária e menos discriminatória (Silva, 2017, p. 21).

Embora o Ministério do Trabalho e o Instituto de Pesquisa Econômica Aplicada (Ipea) ainda não tenham conseguido mapear os impactos da nova lei, evidências empíricas baseadas em dados do Fundo de Garantia do Tempo de Serviço (FGTS) mostram que, em um ano, o número de trabalhadoras com fundo de garantia aumentou de 187,7 mil para mais de 1,3 milhão, conforme consta na reportagem Mulheres são maioria no trabalho doméstico, divulgada pelo Ministério do Trabalho e Previdência Social (MTE, 2016), evidenciando um aumento de trabalhadoras domésticas com carteira assinada (Silva, 2017, p. 22).

Com o aumento no número de empregados domésticos registrados, consequentemente aumenta o número de solicitações de seguro-desemprego dessa modalidade. Observa-se que houve aumento nos três grupos de cidades depois que a nova lei foi aprovada, amparando, então, essa modalidade que até pouco tempo quase não tinha solicitações de benefícios. 


\section{CONSIDERAÇÕES FINAIS}

O objetivo deste trabalho foi realizar um levantamento quantitativo de benefícios do seguro-desemprego que foram solicitados na região metropolitana de Maringá, entre os anos de 2013 e 2017, nas modalidades Formal e Empregado Doméstico. O primeiro passo foi levantar a quantidade de requerimentos cadastrados em cada cidade da região; para isso, foi necessário acessar o site do Ministério do Trabalho e Emprego, baixar todas as solicitações de seguro dos anos em questão e separá-las em grupos de cidades com populações parecidas, o que foi feito, verificando a quantidade habitacional de cada cidade da região segundo o último censo do IBGE, realizado no ano de 2010, para que, assim, uma análise quantitativa pudesse ser elaborada.

Ao trazer essa análise em nível regional, intuiu-se a possibilidade de explicar a importância e a quantidade de pessoas a quem o referido benefício provém renda temporária, enquanto o trabalhador tenta sua recolocação profissional. Pode-se concluir que o benefício de seguro-desemprego em todas as suas modalidades, em especial a Formal e a Empregado Doméstico, que são as mais solicitadas na região metropolitana, é de extrema importância, pois provê renda temporária ao empregado desligado sem justo motivo e o ajuda em sua recolocação no mercado de trabalho. Esse dado revelou a importância de garantir assistência mínima aos trabalhadores em contextos que incitam a crise política e econômica brasileira, uma vez que a curva ascendente de benefícios formais em cidades de porte de 35 mil habitantes tornou-se evidente.

Ainda sobre a urgência da seguridade para os trabalhadores, destacou-se o acesso aos direitos para as trabalhadoras domésticas. Entende-se que o recorte de gênero que pode surgir em futuras pesquisas poderá embasar uma nova visão que empreende em prol da igualdade de gênero e da seguridade em contextos de trabalhos informais. Nesse caso, questiona-se se o impacto do acesso aos direitos trabalhistas em uma atividade que geralmente acontecia em jornadas de trabalhos extremas ou instáveis, de mulheres que possuíam, além do trabalho, mais duas ou três jornadas em suas vidas.

Para a elaboração deste artigo, a principal dificuldade ocorreu diante do acesso à quantidade de seguros-desemprego concedidos na região metropolitana de Maringá/PR. Tais dados foram obtidos depois de uma pesquisa minuciosa no site do MTE, pesquisa que não foi intuitiva, o que pode distanciar a população dos canais de transparência. Trabalhadores que permanecem distantes de seus direitos e possibilidades de seguridade tendem a nutrir possíveis impactos em sua saúde física 
e psicológica. Outra dificuldade foi a possibilidade de recortes interseccionais específicos, como raça, gênero e classe social, não identificados neste trabalho. São temas que podem ser elaborados em futuras pesquisas, as quais, além de trazerem as dimensões citadas, podem investir em comparações com a região de Londrina, comparando, então, as regiões noroeste e norte do estado do Paraná.

\section{REFERÊNCIAS}

Amorim, B., \& Gonzalez, R. (2009). O Seguro-Desemprego como resposta à crise no emprego: Alcance e limites. Boletim Mercado de Trabalho, (40), 43-49. [Nota Técnica].

Brasil. Instituto Brasileiro de Geografia e Estatística. (2017). Estimativa de População. Recuperado de ftp://ftp.ibge.gov.br/Estimativas_de_Populacao/Estimativas_2017/estimativa_TCU_2017_20180618.pdf

Brasil. Ministério do Trabalho e Emprego. (2016). Bolsa de Qualificação Profissional. Recuperado de http://trabalho.gov.br/seguro-desemprego/modalidades/ bolsa-qualificacao

Brasil. Ministério do Trabalho e Emprego. (2015). CODEFAT. Recuperado de http://portalfat.mte.gov.br/codefat/

Brasil. Ministério do Trabalho e Emprego. (2015). Sobre o FAT. Recuperado de http://portalfat.mte.gov.br/codefat/resolucoes-2/resolucoes-por -assunto/geracao-de-emprego-e-renda/linhas-de-creditos-especiais/ fat-giro-cooperativo-agropecuario/sobre-o-fat/

Brasil. Ministério do Trabalho e Emprego. (2016). Seguro-Desemprego Empregado Doméstico. Recuperado de http://trabalho.gov.br/seguro-desemprego/ modalidades/seguro-desemprego-empregado-domestico

Brasil. Ministério do Trabalho e Emprego. (2016). Seguro-Desemprego Formal. Recuperado de http://www.trabalho.gov.br/seguro-desemprego/modalidades/ seguro-desemprego-formal

Brasil. Ministério do Trabalho e Emprego. (2016). Seguro-Desemprego Trabalhador Resgatado. Recuperado de http://trabalho.gov.br/seguro-desemprego/ modalidades/seguro-desemprego-trabalhador-resgatado

Neto, G., \& Zybertajn, H. (1999). O Seguro Desemprego e o perfil dos segurados no Brasil: 1986-1998. In Encontro Nacional de Economia, Anais... Belém: Anpec, 3, 1.903-1.922. 
Ramos, C. (2003). Políticas de geração de emprego e renda: Justificativas teóricas, contexto histórico e experiência brasileira. (Texto para discussão n. 277).

Romero, A. (2003). Trabalho escravo - algumas reflexões. Centro de Estudos Judiciários - CEJ, (22), 119-132.

Santos, L. M. G. M. (2018). Sanando dúvidas sobre o seguro-desemprego. Recuperado de https://luanmesan.jusbrasil.com.br/artigos/535300109/ sanando-duvidas-sobre-seguro-desemprego

Silva, D. (2017). Trabalho Doméstico: As implicações da nova lei da empregada doméstica sobre o sentido, significado e qualidade no trabalho (Dissertação de Mestrado). Viçosa: Universidade Federal de Viçosa. 